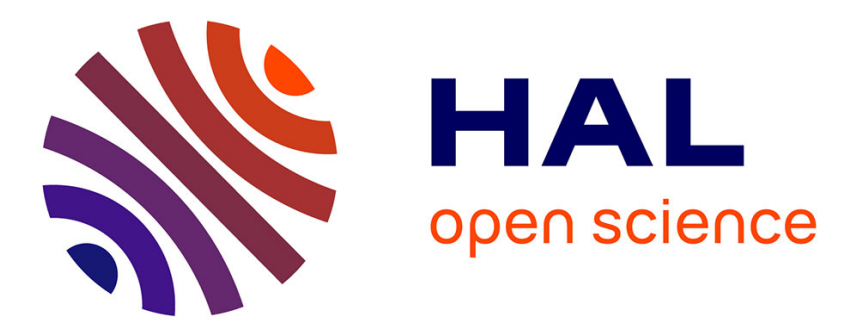

\title{
Fatigue behaviour of impacted composite structures
}

Christian Garnier, Marie-Laetitia Pastor, Bernard Lorrain, Olivier Pantalé

\section{To cite this version:}

Christian Garnier, Marie-Laetitia Pastor, Bernard Lorrain, Olivier Pantalé. Fatigue behaviour of impacted composite structures. Composite Structures, 2013, vol. 100, pp. 443-450. 10.1016/j.compstruct.2012.12.025 . hal-00839629

\section{HAL Id: hal-00839629 \\ https://hal.science/hal-00839629}

Submitted on 28 Jun 2013

HAL is a multi-disciplinary open access archive for the deposit and dissemination of scientific research documents, whether they are published or not. The documents may come from teaching and research institutions in France or abroad, or from public or private research centers.
L'archive ouverte pluridisciplinaire HAL, est destinée au dépôt et à la diffusion de documents scientifiques de niveau recherche, publiés ou non, émanant des établissements d'enseignement et de recherche français ou étrangers, des laboratoires publics ou privés. 


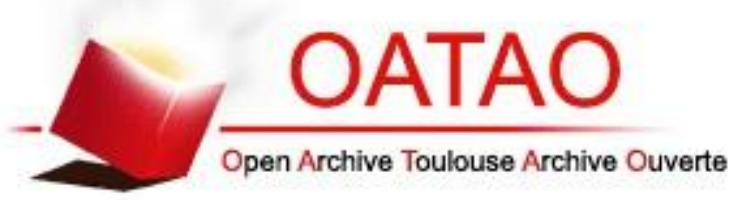

Open Archive Toulouse Archive Ouverte (OATAO)

OATAO is an open access repository that collects the work of Toulouse researchers and makes it freely available over the web where possible.

This is an author-deposited version published in: http://oatao.univ-toulouse.fr/ Eprints ID: 8391

To link to this article: DOI:10.1016/j.compstruct.2012.12.025

Official URL: $\underline{\text { http://dx.doi.org/10.1016/j.compstruct.2012.12.025 }}$

\section{To cite this version:}

Garnier, Christian and Pastor, Marie-Laetitia and Lorrain, Bernard and Pantalé, Olivier Fatigue behaviour of impacted composite structures. (2013) Composite Structures, vol. 100 . pp. 443-450. ISSN 0263-8223

Any correspondence concerning this service should be sent to the repository administrator: staff-oatao@inp-toulouse.fr 


\title{
Fatigue behaviour of impacted composite structures
}

\author{
Christian Garnier ${ }^{\mathrm{a}}$, Marie-Laetitia Pastor ${ }^{\mathrm{b}}$, Bernard Lorrain ${ }^{\mathrm{a}}$, Olivier Pantalé ${ }^{\mathrm{a}}$ \\ ${ }^{a}$ Université de Toulouse, INP de Toulouse, ENI de Tarbes, Laboratoire Génie de Production, \\ avenue d'Azereix, B.P. 1629, 65016 Tarbes, France \\ ${ }^{\mathrm{b}}$ Université de Toulouse, UPS, Institut Clément Ader, IUT de Tarbes, rue Lautréamont, \\ 65016 Tarbes, France
}

\begin{abstract}
The aim of this study was to compare the mechanical behaviour of different impact-damaged composite materials. Three composite materials were realized using the Liquid Resin Infusion process (LRI) according to three different cycles of polymerization. Thus the temperature of the glass transition of the resin was controlled and the influence of this parameter was then determined.

In accordance with the aeronautical use of composite materials, the plates were subjected to Barely Visible Impact Damage (BVID). Two experimental methods were developed to ensure that impact conditions were respected. The first method, using the numerical digitalization of surfaces made it possible to reconstruct the defect. Thus the residual indentation could be measured. This indentation had to be lower than $0.3 \mathrm{~mm}$. The second method, using passive infrared thermography, enabled the thermal cartography on the surface to be determined. The size of the damage area was then obtained.

Through the use of these two methods, the best cycle of polymerization was determined and fatigue tests were carried out to estimate the evolution of the defect. For this purpose and in compliance with impact and fatigue testing standards, a new and adapted sample was imagined (FAI sample). The fatigue testing conditions were determined to avoid buckling effects and to limit the rise of the temperature of the sample. An experimental method using infrared thermography was then developed to follow the size evolution of the defect. This real time evolution was then compared to the loss of rigidity of the sample.
\end{abstract}

Keywords: Fatigue (D), Impacted Composite (A), BVID (B), InfraRed Thermography (D)

\section{Introduction}

Impact damage is an important issue in designing composite structure. Composites, contrary to metallic materials, can sustain impact without any visible trace on the surface. Nevertheless, this dynamic stress may modify the internal cohesion of the structure. The mechanical properties may also be reduced [1].

Because of the heterogeneity and the anisotropy of composite materials, four major modes of damage can be identified:

- matrix cracking (microscopic scale) [2],

- delamination $[3,4]$,

- break and buckling of fibres [5],

- penetration and associated collapses $[6,7]$.

These undesirable inclusions strongly affect behaviour of the composite under dynamic stress. In this study, the low energy and low speed impacts are studied because they represent outflight defects: defects due to the manufacturing process, storage, service or runway accidents. 
The BVID energy, for hail impacts or service tool fall and for materials used in this study, is defined between 22 and 25 Joules, which corresponds to a residual indentation of $0.3 \mathrm{~mm}$.

It is interesting to study defect due to impact but it is also interesting to follow its evolution during a loading cycle. Indeed, the fatigue behaviour of composite structures is an important issue for aeronautic manufacturers. Cyclic solicitations can be very damaging. Some studies deal with the damaging mechanisms of unidirectional fibres loaded in tensile-tensile. Also the role of the fibres, the matrix and their interface in fatigue behaviour are understood [8].

Non-destructive testing is used in order to check structure integrity (material stiffness) and to determine the damage type. The X-rays, eddy current, acoustic emission or infrared thermography $[9,10,11,12,13,14,15,16,17]$ enable the damage initiation and propagation during fatigue tests to be detected.

In this study, infrared thermography is used. According to thermo-mechanics, any deformation of a solid material (due to damage initiation or propagation) is transformed into heat flow [16]. Infrared thermography is a non-contact, non-destructive technique that is quick and simple to implement. It is used more and more for fatigue tracking $[18,19,20,21$, $22,23,24,25,17]$, material damage and the determination of fatigue data (fatigue limit, damaged zone) [19, 26, 27].

To begin with, in this paper, the methodologies of non-destructive testing used after impacts or fatigue tests are explained. Secondly, impact and fatigue tests are presented. Finally the results obtained are discussed and analysed.

\section{Methodology of Non-Destructive Testing}

\section{I.1 Non-destructive testing of a damaged area (residual penetration and infrared thermography)}

The aim of this study is to keep to BVID impact in order to ensure the integrity of the damaged composite. The measurement of the residual penetration and the size of the damaged area can verify the BVID. Two non-destructive methods are also developed. The first, based on 3D digitalisation, highlights the residual penetration; the second, based on infrared thermography, gives some indication concerning the size of the damaged area.

\section{Measurements of the residual penetration by $3 D$ digitalisation}

Surface roughness due to the pulling-up of woven fabric disturbs the measurements carried out by traditional means (comparator, adjustable leg). Optical measurement is therefore selected. The damaged area is reconstructed and the residual penetration is measured. The acquisition of 3D coordinates is carried out using the GOM Tritop system by 3D photogrammetry and surface digitalisation by fringe projection is carried out using the GOM Atos system. The Tritop system is equipped with a 12 Megapixel camera coupled to a triangulation algorithm (Figure 1). Graduated rulers adjust the scale of the system, and the coded points create a reference mark. Uncoded points, or stickers, are stuck on the specimen. The algorithm makes it possible to triangulate an uncoded point thanks to three coded points. Consequently, all the stickers are located by a number and their 3D coordinates: the digitized part is located in the reference mark. The position of the base plate is then obtained. It is used as support to the damaged specimens which will be digitalized. 


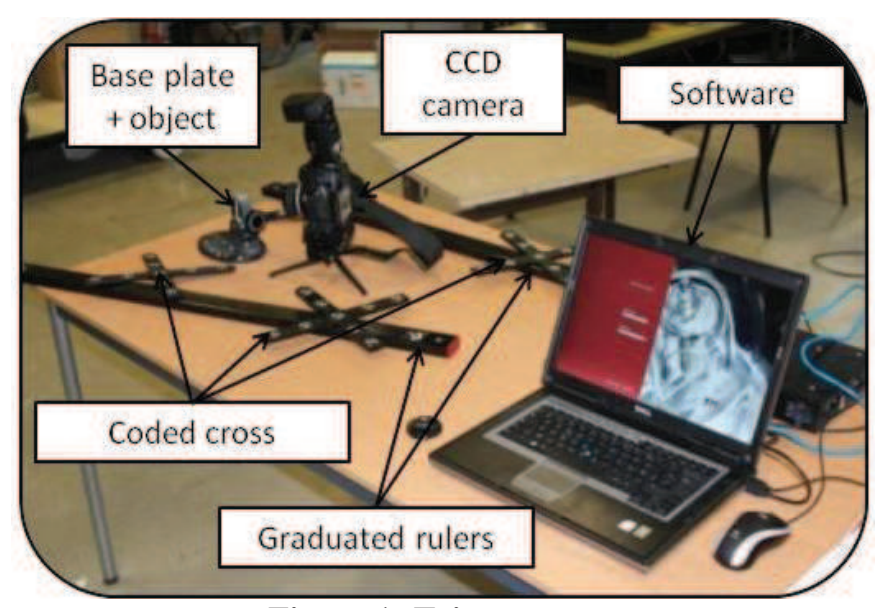

Figure 1: Tritop system

The Atos system (Table 1) is equipped with the 2D Aramis head (Figure 2) coupled to a polygon mesh algorithm and post-processing, called Atos. The 3D coordinates of the base plate are obtained with the Tritop output file. The specimen is held by the base plate. It is swept by a gauged fringe network which is deformed by area geometry. A CCD camera captures this deformation and thanks to the meshing algorithm, the specimen facet edge is created. During the meshing construction of the damaged area, no filter is used for meshing in order to avoid losing information concerning residual penetration: it is about some tenth.

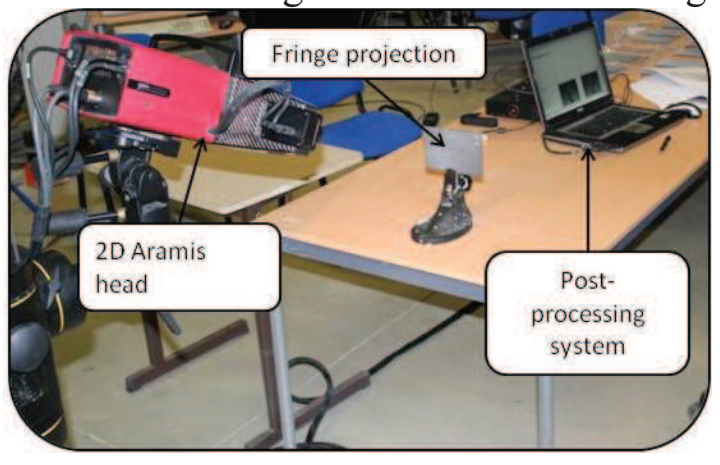

Figure 2: Experimental setup - area digitalisation

\begin{tabular}{|c|c|}
\hline Number of measured points & 160000 \\
\hline Number of triangles & 310000 \\
\hline Measurement time (seconds) & 1 \\
\hline Lens & 500 \\
\hline Measured area $\left(\mathrm{mm}^{2}\right)$ & $485 \times 385$ \\
\hline Accuracy $(\mathrm{mm})$ & 0.02 \\
\hline
\end{tabular}

Table 1: Technical characteristics of 2D Aramis head

Post-processing is realised in four stages:

- meshing,

- definition of the $\mathrm{z}=0$ plan,

- calculation of average plan deviations,

- deviation cartography.

\section{Measurement of the damaged area by active infrared thermography}

The thermal waves are transmitted to the specimen by means of a halogen lamp at a distance of $150 \mathrm{~mm}$ (Figures 3-4). The temperature field inside the specimen is measured on the surface by the infrared camera FLIR MWIR retrofitted Titanium. It has a focal plan of $320 \times 240$ pixels and a thermal resolution of $20 \mathrm{mK}$. The halogen lamp transmits the heat flow for 5 seconds. A film records the temperature field on the surface of the specimen at a frequency of $152 \mathrm{~Hz}$. It lasts for 30 seconds in order to record the temperature rise $(5 \mathrm{sec})$ and the beginning of the decrease in temperature $(25 \mathrm{sec})$. 


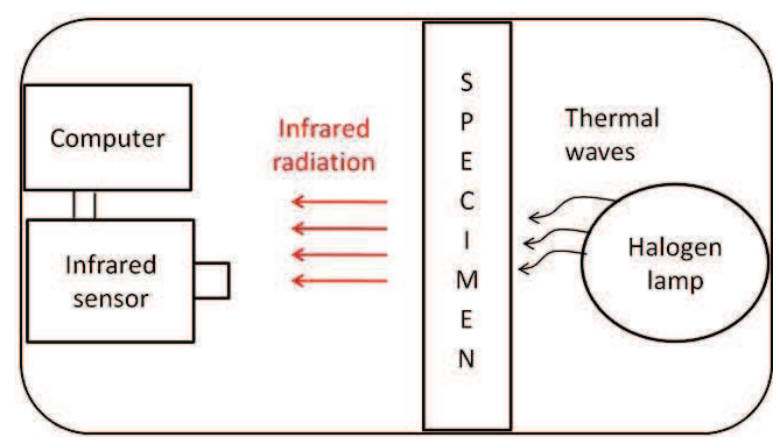

Figure 3: Infrared thermography principle

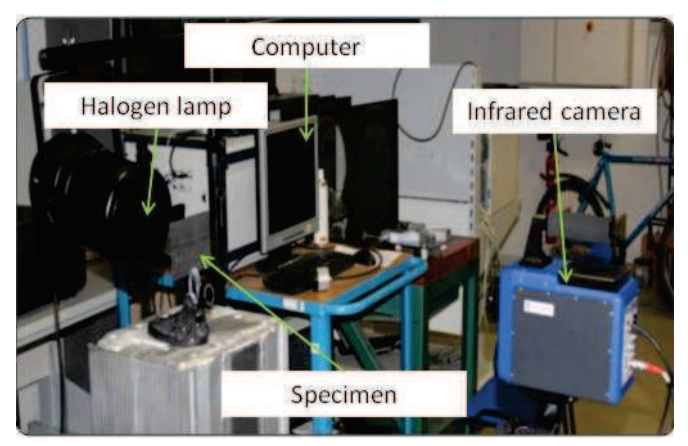

Figure 4: Experimental setup - NDT by infrared thermography

The film is post-treated in order to reduce the maximum of noise due to the experimental environment and to automate the calculation of the defect size (Table 2).

\begin{tabular}{|l|l|l|}
\hline 1 & $\begin{array}{l}\text { Definition of the studied area: } \\
\text { specimen edge } \\
3\end{array}$ & $\begin{array}{l}\text { Recording of the average of the first } \\
\text { image to the whole film images }\end{array}$ \\
\hline 5 & $\begin{array}{l}\text { fubtraction of the initial average } \\
\text { using the ImageJ software } \\
\text { observed defect }\end{array}$ & $\begin{array}{l}\text { Image recording at the inflection } \\
\text { Automation of the defect calculation }\end{array}$ \\
\hline
\end{tabular}

Table 2: Data processing obtained by NDT - infrared thermography

The size of the defect is obtained by ImageJ software (defect induced by BVID impact). 


\section{I.2 Control in real time of the evolution of the impacted area by fatigue}

\section{Measurement in real time of the damaged area evolution by infrared thermography}

The aim is to determine the evolution of the area damaged by a BVID impact during a fatigue test and also to follow the evolution of the mechanical properties of the structure.

The infrared camera is thus coupled on the Instron 8800 controller via an electronic card. The infrared camera is started with a definite limit in load.

Toubal [28] used a traditional method to follow the damage evolution of a carbon/epoxy specimen with hole. The substraction of the temperature distribution between the initial gradient and the current one is performed. Hotter areas appear and reveal the damaged area evolution.

A new tracking method using infrared thermography in real time is developed by coupling the NDT images and the infrared images in real time [17]. Initially, an NDT inspection by infrared thermography is carried out on the damaged specimen. An infrared cartography is thus obtained and damaged areas are determined. Following this, the fatigue tracking gives an infrared cartography of the temperature field for all the cycles. The method consists of subtracting the NDT image to the image obtained during the fatigue test for a given cycle number (Figure 5). Two important pieces of information are provided: the size of the initial defect due to BVID impact and its evolution after a fatigue test.

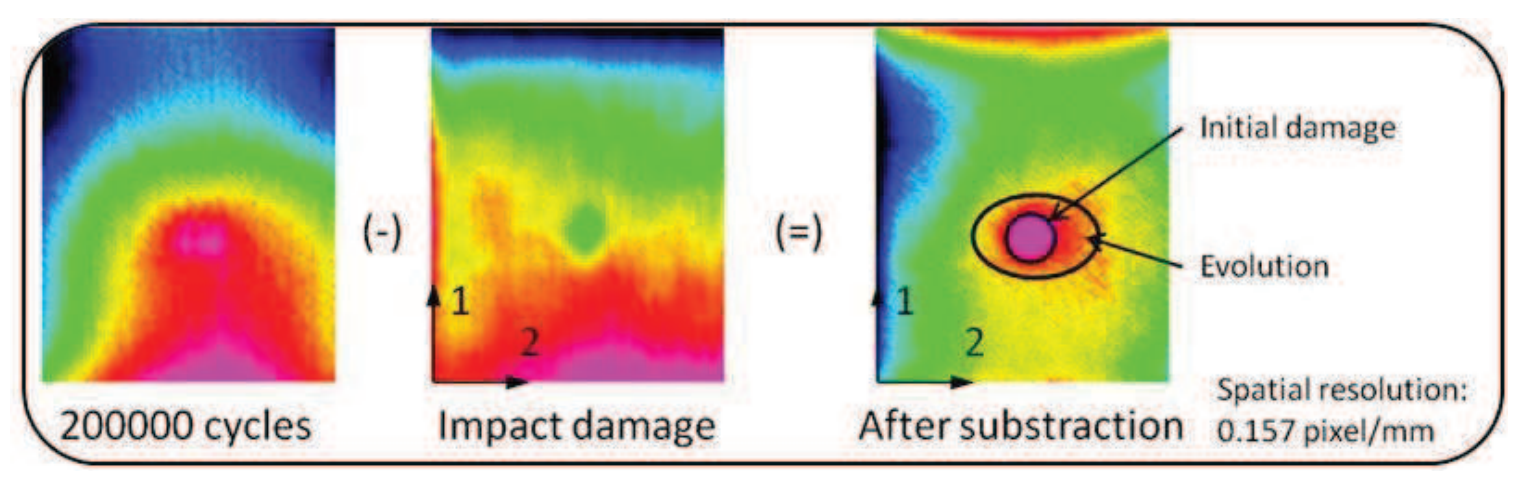

Figure 5: Subtraction method

\section{Experimental device and results}

\section{II.1 Material}

The material for this study is carbon fibre reinforced with Epoxy resin. It is obtained by the liquid infusion process. This process is advantageous from an economic point of view and its use is tending to spread within the aeronautical industry. The components of the material are 5-end satin carbon fabric called G926 and RTM6 epoxy resin. As the aim of the study is to compare impact behaviour of composite material, several cure cycles were tested. Thus their influence could be estimated.

The quality of the cure cycle is quantified by the rate of polymerization of the resin. Indeed, the mechanical characteristics of the composite are influenced by this rate of polymerization and its effects on the temperature of glass transition $T_{\mathrm{g}}$. This temperature of glass transition depends on several parameters: the speed of temperature rising, the maximum value of the cure stages temperature and the time this temperature is maintained. A study realized in our 
laboratory dealt with a cure cycle recommended by the resin manufacturer and optimized it [29].

These two different cure cycles are used for the realization of the composite plates, with a third one for which the time of maintenance at the reticulation stage temperature was reduced. Thus the resin should be under-polymerized. With this choice the bending rigidity of the third composite is voluntarily decreased and its influence on the impact behaviour can be estimated. The three cure cycles are referred to as:

- Cycle 1: optimized cycle,

- Cycle 2: resin manufacturer recommended cycle,

- Cycle 3: under polymerized cycle.

The parameters used in the realization of these three cure cycles are given in the following table (Table 3 ).

\begin{tabular}{|l|c|c|}
\hline & Temperature rising speed & Polymerization stage \\
\hline Cycle 1 & $2{ }^{\circ} \mathrm{C} / \mathrm{min}$ & $1 \mathrm{~h} / 185^{\circ} \mathrm{C}$ \\
\hline Cycle 2 & Instantaneous & $2 \mathrm{~h} / 150^{\circ} \mathrm{C}$ \\
\hline Cycle 3 & Instantaneous & $30 \mathrm{~min} / 150^{\circ} \mathrm{C}$ \\
\hline
\end{tabular}

Table 3: Cycles of polymerization

a) Material properties

In the aeronautical industry, maximum acceptable porosity is about $2.5 \%$. Under this limit it is assumed that the porosity distribution is homogeneous over the whole plate, without particular accumulation in an unspecified zone. The porosity rates obtained for the three cycles of polymerization are shown in the following table (Table 4):

\begin{tabular}{|c|c|c|c|}
\hline & Cycle 1 & Cycle 2 & Cycle 3 \\
\hline Density & 1.484 & 1.496 & 1.506 \\
\hline Porosity rate (\%) & 1.109 & 1.158 & 1.108 \\
\hline Fibre rate (\%) & 55.9 & 58 & 59.3 \\
\hline
\end{tabular}

Table 4: Material characteristics according to cycles of polymerization

The analysis of the results shows a quasi-identical density for all three cycle. The determination of the fibre rate follows the same pattern with a $6 \%$ variation for the three cycles. The porosity rate is lower than the acceptable $2.5 \%$. Consequently the properties of the materials are located in a level of acceptability for an aeronautical application of order 1 , I.E. for a use in structural parts.

b) Mechanical properties

The mechanical behaviour of the composite plate is strongly dependent on the organization of the macromolecular chains of the resin. As the temperature of glass transition $T_{g}$ evolves according to these macromolecular organizations, it seems necessary to perform a Differential Scanning Calorimetry (DSC) and a rheological analysis in order to determine the temperature of glass transition according to the cure cycles. Thus information about the rate of reticulation of the resin could be obtained.

The DSC analysis gives a first calorimetric value of the temperature of glass transition $T_{g}$, whereas the rheological analysis gives it again with a mechanical one $\mathrm{T}_{\alpha}$.

In the following table (Table 5) the results obtained with both analysis are compared with these expected for the resin [29]. 


\begin{tabular}{|c|c|c|c|}
\hline & Cycle 1 & Cycle 2 & Cycle 3 \\
\hline $\mathrm{T}_{\mathrm{g}}$ expected $\left({ }^{\circ} \mathrm{C}\right)$ & 210 & 185 & 170 \\
\hline $\mathrm{T}_{\mathrm{g}} \mathrm{DSC}\left({ }^{\circ} \mathrm{C}\right)$ & 211 & 185 & 168 \\
\hline $\mathrm{T}_{\mathrm{g}}$ Rheometer $\left({ }^{\circ} \mathrm{C}\right)$ & 212 & 186 & 168 \\
\hline $\mathrm{T}_{\alpha}$ Rheometer $\left({ }^{\circ} \mathrm{C}\right)$ & 207 & 181 & 173 \\
\hline
\end{tabular}

Table 5: Glass transition temperature according to cycles of polymerization

These results show that the temperature of glass transition obtained with the three cure cycles are different. The higher the temperature of the resin during the cure cycle is, the higher is the temperature of glass transition. The three composite plates realized have different macromolecular kinematics at different temperatures but also a different ductility. The higher the temperature of glass transition is, the more brittle is the behaviour of the composite material. These phenomena will be observed during impact testings.

\section{II.2 Impact testing}

\section{Sample}

The impact sample should not be sensitive to edge effects during the test. Thus standard ASTM D 7136 standardizes its dimensions. Moreover in order to controlling the damage propagation, the standard recommends the use of minimum $4 \mathrm{~mm}$ thickness sample. The stacking sequence used to obtained this thickness is: $\left[\left[0^{\circ} / 45^{\circ}\right] 3\right] \mathrm{s}$. The real thickness is then $4.52 \mathrm{~mm}$. The size of the sample is $150 \times 100 \times 4.52 \mathrm{~mm} 3$.

The composite plates are always realized using the three cure cycles presented above.

\section{Testing device}

The testing device is an impact-testing instrument from MTT (Material Testing Technology). Its maximum capacity is $60 \mathrm{~J}$ and it is equipped with a hemispheric head of diameter $16 \mathrm{~mm}$ (Figure 6). The falling mass is $3 \mathrm{~kg}$ and the maximum height of fall is $1 \mathrm{~m}$. The use of additional masses enables testing with higher energies. A mechanical system clamps the sample (Figure 7) and an anti-rebound system stops the falling mass after impact. 


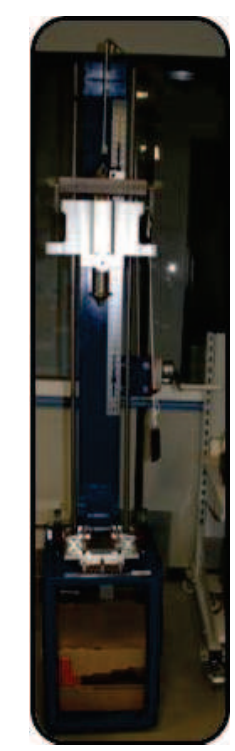

Figure 6: Impact testing instrument MTT

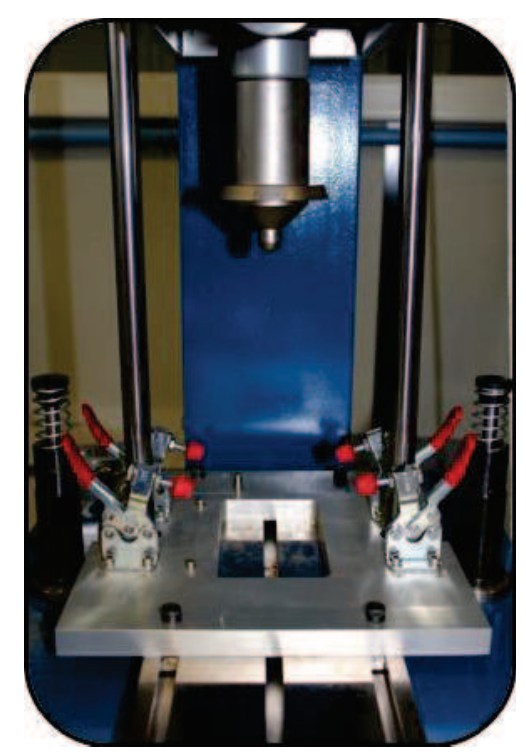

Figure 7: Sample mechanical clamping

\section{Damage checking}

To be sure that the impact conditions are really BVID, the methods of control presented previously have been applied to the samples. Table 6 gives the results obtained during the control of the residual indentation by surface digitalization and the size of the damaged area (ZE) by infrared thermography.

\begin{tabular}{|l|c|c|c|}
\hline & Cycle 1 & Cycle 2 & Cycle 3 \\
\hline Residual indentation $(\mathrm{mm})$ & 0.275 & 0.237 & 0.324 \\
\hline Damaged area $\left(\mathrm{mm}^{2}\right)$ & 495.2 & 449.3 & 416.7 \\
\hline
\end{tabular}

Table 6: Impact tests results

According to the depth of the residual indentation, all the results are close to $0.3 \mathrm{~mm}$. This is the limit of detectability, so the impact is really in the BVID domain. All the tests are repetitive [30] which enables the average of the obtained values to be presented.

As regards the size of the damaged area, it decreases from cycle 1 to cycle 3 . These results follow the same pattern as the temperature of glass transition. Indeed, the higher the temperature of glass transition $\left(\mathrm{T}_{\mathrm{g} \text { Cycle } 1}>\mathrm{T}_{\mathrm{g} \text { Cycle } 2}>\mathrm{T}_{\mathrm{g} \text { Cycle } 3}\right)$, the more polymerised and the more brittle is the resin. Moreover, this high rate of polymerization (97\% for cycle 1$)$ induces higher stiffness of the sample. Thus during impact testing, part of the energy is absorbed by the deformation of the plate. So the greater the stiffness of the plate is, the lower is the energy absorption. The result is that the energy of degradation due to the wave propagation is greater and causes more damage to the sample.

In conclusion, according to the influence of the impact, cycle 3 with its $0.324 \mathrm{~mm}$ of residual indentation can be considered as non-BVID. The damage induced by cycle 1 is greater than that of cycle 2 . It seems logical then to continue the study with only cycle 2 , to optimize the mechanical properties of the material. 


\section{II.3 Fatigue Testing}

\section{Test device and sample}

In order to simultaneously respect the impact testing standards (ASTM D 7136) and fatigue testing standards (NF EN ISO 527-4), a new sample has been developed. It associates the width and the thickness of the impact test sample and the length of the fatigue test sample. This sample will be now referred to as the FAI sample (Figure 8). This sample presents large dimensions and high mechanical properties so all the mechanical tests require a high capacity testing machine. The tests were carried out on an INSTRON 1345 machine equipped with a load cell of $250 \mathrm{kN}$ in dynamic. Tests were controlled in load and the temperature of the sample was checked with a FLIR Titanium thermal camera.

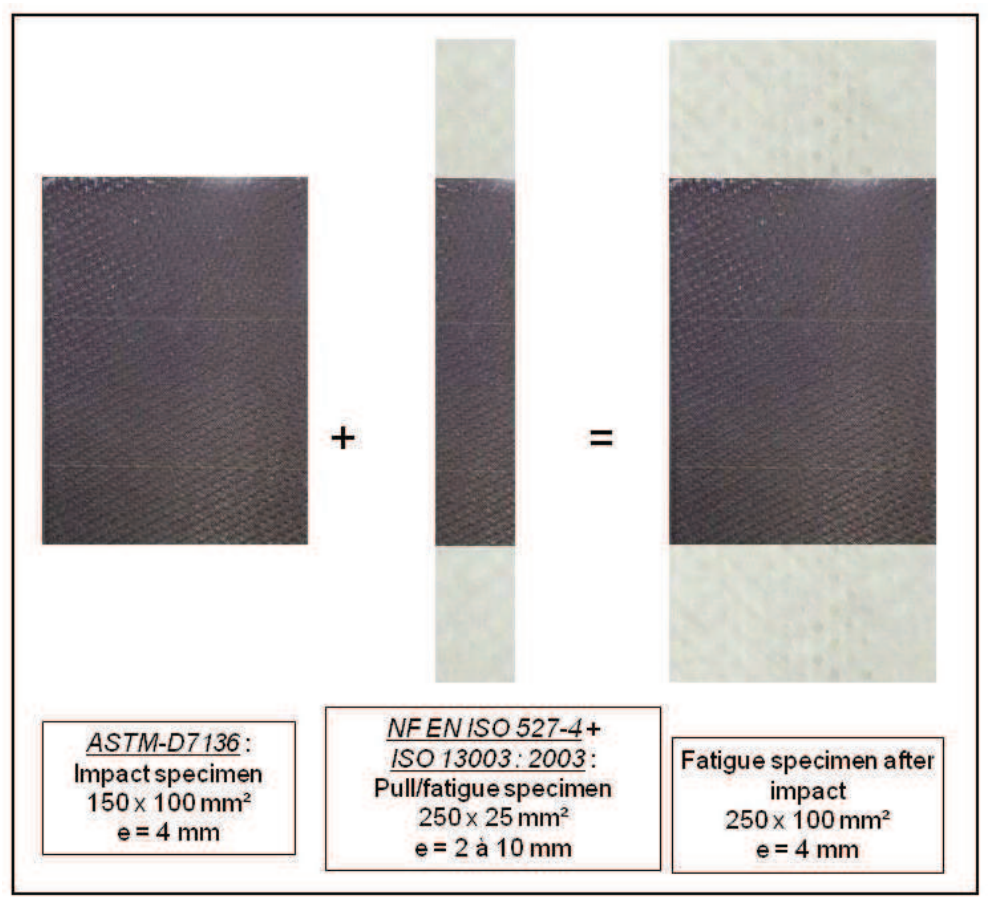

Figure 8: Samples

\section{Fatigue cycle}

In order to respect the conditions of use of the composite parts and with an aim of generating controlled damage, a standard cycle of fatigue was developed. The objective is to enter the prejudicial compression field while avoiding buckling phenomena. The shape of this tensilecompressive cycle is presented on Figure 9. 


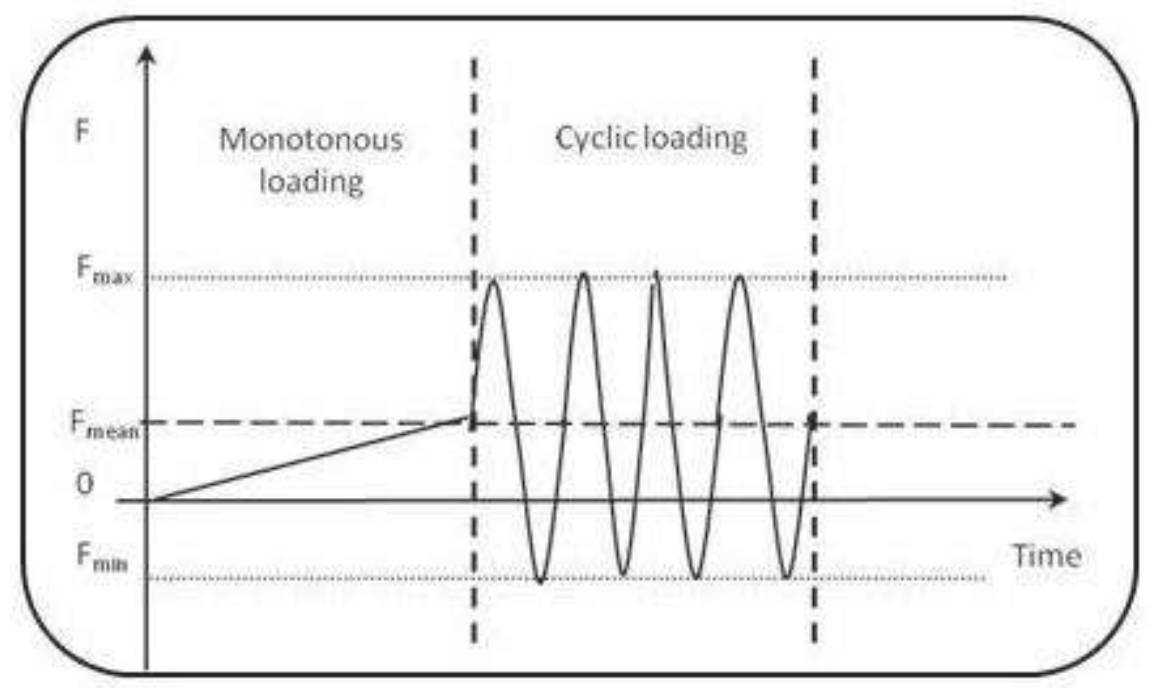

Figure 9: Standard cycle of fatigue

The first part of the test is a monotonous rise to the average load. Thus the initial modulus of elasticity of the sample can be determined. Thereafter the fatigue testing begins with a load ratio $\mathrm{R}=0.2$. For each cycle an instantaneous modulus of elasticity can be measured. The damage can be estimated by the loss of stiffness of the sample.

The standard fatigue test NF EN ISO 527-4 stipulates that during fatigue testing the rise of the sample temperature should not exceed $10^{\circ} \mathrm{C}$. A solicitation frequency test of maximum $3 \mathrm{~Hz}$ makes it possible to respect this condition. The maximum load applied to the sample is $65 \%$ of the ultimate load i.e. $130.5 \mathrm{kN}$. During the test, cycles of hysteresis are plotted and damage can be estimated.

The Infrared camera enables the temperature field on the surface of the sample to be visualised. In accordance with the procedure developed to track the test, periodical films are recorded and associated with the cycles of hysteresis. The obtained film is post-treated to extract cartographies for the different cycles (Figure 10).

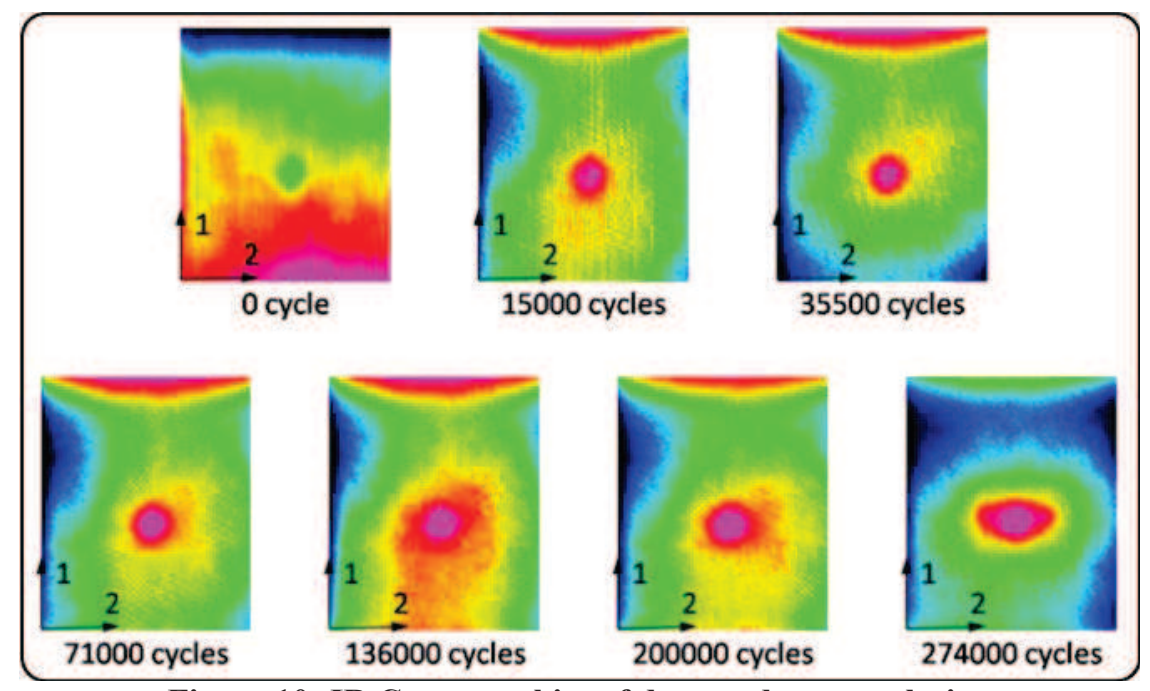

Figure 10: IR Cartographies of damaged area evolution

The different IR cartographies show the evolution of the damaged area. It is the possible to correlate this evolution with the loss of stiffness of the sample. The testing procedure of real time measurement of the damage area evolution by passive infrared thermography was performed on 3 impacted samples obtained by the cure cycle 2 . To begin with, the evolution 
of the defect along axes 1 and 2 of the three samples is plotted (axis 1 of the sample is the same as the loading one, axis 2 is the perpendicular one (Figure 11)).

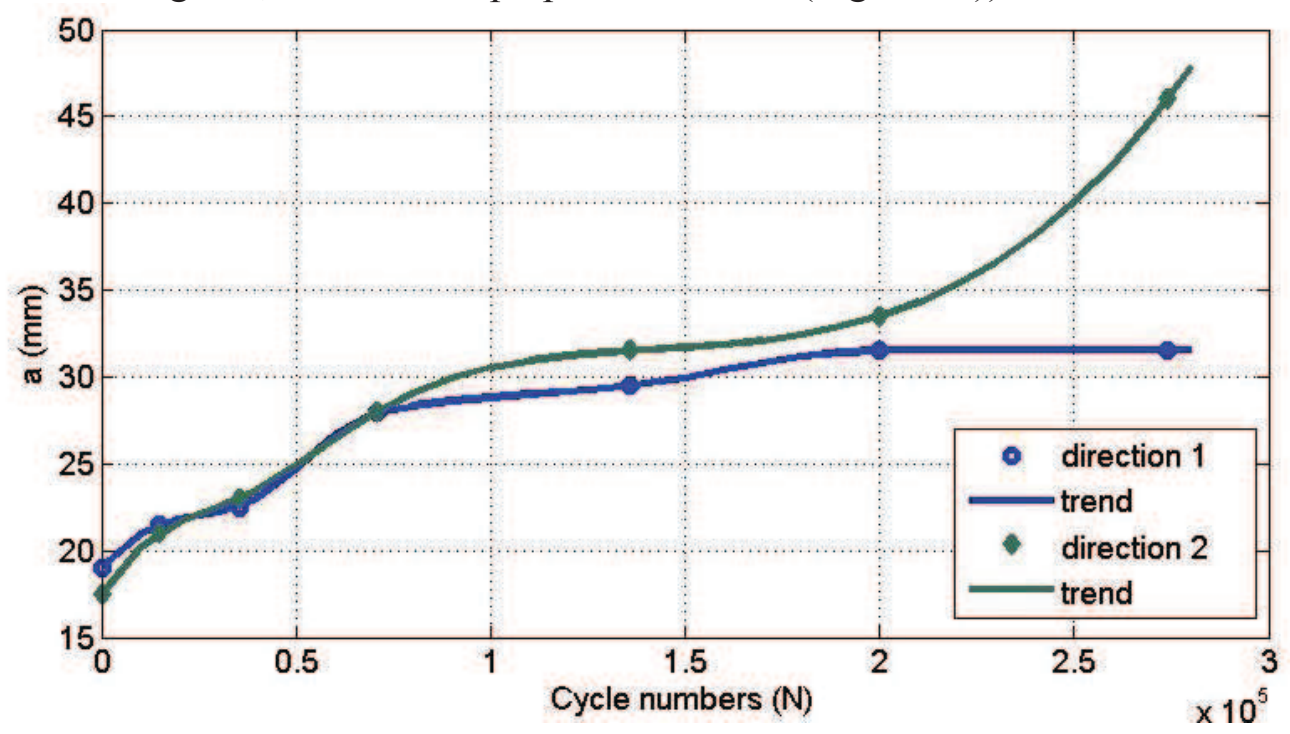

Figure 11: Impact defect evolution along the 2 directions

From this first plotting, we note that at the beginning of the test, the defect evolves in the two directions of the loading plane. After stabilization the defect propagation appears only along the direction perpendicular to the load direction (direction 2).

Secondly, the defect evolution for the three samples is plotted (Figure 12).

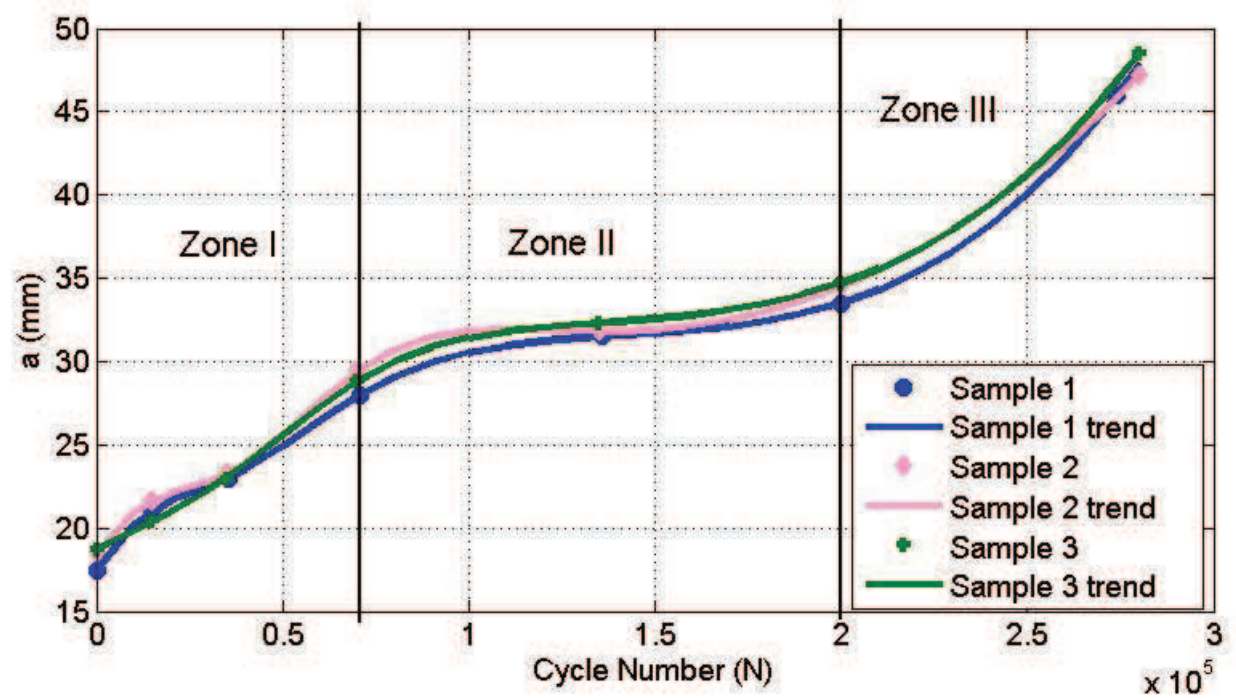

Figure 12: Defect evolution for the 3 samples

The impact damage of the three samples follows the same trend. So, the method used can then be validated. In fact, the evolution is qualitatively and quantitatively the same during all the fatigue tests. For example, with 200000 cycles, the values of the defect are respectively 33.5, 34.5 and $34.7 \mathrm{~mm}$ for the 3 samples. The standard deviation is then 0.643 for an average of $34.23 \mathrm{~mm}$. Variation is about $2 \%$. 
For all the tests the damage appears at the beginning and quickly increases until a stabilisation at around 70000 cycles. Then a second phase begins up until 200000 cycles where advanced damaging with a quick change of the size defect appears. This evolution in three phases is in perfect agreement with the modes of progressive damaging: initiation, stabilization and quick rupture [31]. This trend relates to the works of Jamison [31] and Mao [32] who showed that the evolution of residual stiffness during fatigue testing follows these three phases. The only difference with the present study is that the composite plates presented here are already damaged by impact

\section{Conclusion}

The fatigue of damaged composite structures manufactured by LRI was investigated in this study. The following conclusions can be drawn from the experimental results obtained:

- the cure cycle C2 gives the best mechanical characteristics and it gives a BVID energy. This cycle has an instantaneous rise in temperature and a long temperature stabilisation stage,

- a new method of defect tracking evolution is developed from subtraction methods,

- the initial defect and its propagation could thus be highlighted,

- the mechanical data obtained during fatigue testing shows that the evolution in the stiffness of the damaged composite follows the Jamison model in three phases [31],

- for damaged structures, the damage evolves from the specimen centre (BVID impact area).

It would be interesting to post-treat thermographic films with filters in order to reduce experimental noise or to calculate heat sources in order to preserve only the dissipated energy. Another prospect would be to link the fatigue testing machine, infrared camera and a halogen lamp in order to have a NDT image of the defect. The acquisition of the damaged area evolution would then be progressive.

\section{References}

[1] S. Abrate. Modeling of impacts on composite structures. Composite Structures, 51(2):129-138, 2001.

[2] M.O.W Richardson and M.J. Wisheart. Review of low-velocity impact properties of composite materials. Composites Part A: Applied Science and Manufacturing, 27(12):1123-1131, 1996.

[3] H.S.T. Wu and G.S. Springer. Measurements of matrix cracking and delamination caused by impact on composite plates. Journal of Composite Materials, 22(6):518-532, 1988.

[4] W. Cui and W.R. Wisnom. A combined stress-based and fracture-mechanicsbased model for predicting delamination in composites. Composites, 24(6):467-474, 1993.

[5] G. Dory. Impact damage in composites - development, consequences and prevention. In $6^{\text {th }}$ international conference on composite materials, 1988.

[6] S. Guinard, O. Allix, D. Guedra-desgeorges, and A. Vinet. Tenue aux petits chocs des structures en stratifié composite. Technical report, Annales des composites "délaminage des multi-couches : phénomènes, modèles et critères", 2000 . 
M. Kaminski and J.F. Maire. Tolérance aux dommages des structures composites impactées : un état des lieux. In Tolérance aux dommages sur les structures composites (impact faible énergie), 2009.

C.K.H. Dharan. Fatigue failure mechanisms in an unidirectionally reinforced composite material. Fatigue of composite materials, ASTM STP 569:171-188, 1975.

L. Xi Cong and C. Bathias. Fatigue damage development in Al2O3/Al composite. Composites, 24:1127-1139, 1993.

X.L. Gong, A. Laksimi, and M.L. Benzeggagh. Nouvelle approche de l'émission acoustique et son application à l'identification des mécanismes d'endommagement dans les matériaux composites. Revue des composites et

matériaux avancés, 8:7-23, 1998 .
Y.A. Dzenis. Cycle-based analysis of damage and failure in advanced composites under fatigue: 1 . experimental observation of damage development within loading cycles. International Journal of Fatigue, 25(6):499 - 510, 2003. X.E. Gros. An eddy current approach to the detection of damage caused by low-energy impacts on carbon fibre reinforced materials. Materials \& Design, 16(3): $167-173,1995$.

X.E. Gros, J. Bousigue, and K. Takahashi. NDT data fusion at pixel level. NDT \& E International, 32:283-292, 1999.

F. Lachaud. Délaminage des matériaux composites à fibres de carbone et à matrices organiques : étude numérique et expérimentale, suivi par émission acoustique. $\mathrm{PhD}$ thesis, ENSICA, 1997.

. Valentino, A. Ruosi, G. Peluso, and G.P. Pepe. Structural health monitoring of materials by high critical temperature squid. Physica C: Superconductivity, 372-376(Part 1):201 - 208, 2002.

A. Chrysochoos. La thermographie infrarouge, un outil en puissance pour étudier le comportement des matériaux. Mécanique \& Industries, 3(1):3 - 14, 2002.

C. Garnier, B. Lorrain, and M.L. Pastor. Impact damage evolution under fatigue loading by infrared thermography on composite structures. In International Conference on Experimental Mechanics (ICEM 14), 2010.

M.P. Luong. Infrared thermographic scanning of fatigue in metals. Nuclear Engineering and Design, 158(2-3):363 - 376, 1995.

M.P. Luong. Fatigue limit evaluation of metals using an infrared thermographic technique. Mechanics of Materials, 28(1-4):155 - 163, 1998.

G. La Rosa and A. Risitano. Thermographic methodology for rapid determination of the fatigue limit of materials and mechanical components. International Journal of Fatigue, 22(1):65 - 73, 2000.

P.K. Liaw, H. Wang, L. Jiang, B. Yang, J.Y Huang, R.C. Kuo, and J.G. Huang. Thermographic detection of fatigue damage of pressure vessel steels at 1,000 hz and 20 hz. Scripta Materialia, 42(4):389 - 395, 2000.

B. Yang, P.K. Liaw, H. Wang, L. Jiang, J.Y. Huang, R.C. Kuo, and J.G. Huang. Thermographic investigation of the fatigue behavior of reactor pressure vessel steels. Materials Science and Engineering: A, 314(1-2):131 - 139, 2001. B. Yang, P.K. Liaw, G. Wang, M. Morrison, C.T. Liu, R.A. Buchanan, and Y. Yokoyama. In-situ thermographic observation of mechanical damage in bulkmetallic glasses during fatigue and tensile experiments. Intermetallics, 12(1011):1265 - 1274, 2004. 
[24] R. Steinberger, T.I. Valadas Leitao, E. Ladstätter, G. Pinter, W. Billinger, and R.W. Lang. Infrared thermographic techniques for non-destructive damage characterization of carbon fibre reinforced polymers during tensile fatigue testing. International Journal of Fatigue, 28(10):1340 - 1347, 2006.

[25] T. Ummenhofer and J. Medgenberg. On the use of infrared thermography for the analysis of fatigue damage processes in welded joints. International Journal of Fatigue, 31(1):130 - 137, 2009.

[26] P. Brémond, and P. Potet. Lock-in themography: a tool to analyse and locate thermomechanical mechanisms in materials and structures. In Thermosense XXIII, 2001.

[27] M. Quaresimin. Fatigue of woven composite laminates under tensile and compressive loading. In Tenth European Conference on Composite Materials (ECCM 10), 2002.

[28] L Toubal, M. Karama, and B. Lorrain. Damage evolution and infrared thermography in woven composite laminates under fatigue loading. International Journal of Fatigue, 28(12):1867-1872, 2006.

[29] L. Poussines, V. Nassiet, and B. Hassoune Rhabbour. How to modify resin formulations to optimize infusion process. In $3^{\text {rd }}$ International Conference on Advanced Computational Engineering and Experimenting, 2009.

[30] C. Garnier. Etude du comportement dynamique des structures composites réalisées par LRI: application à l'impact et à la fatigue, $\mathrm{PhD}$ thesis, Université de Toulouse, 2011.

[31] R.D. Jamison, K. Schulte, K.L. Reifsnider, and W.N. Stinchcomb. Characterization and analysis of damage mechanism in tension-tension fatigue of graphite/epoxy laminates - effect of defects in composite materials. American Society for Testing and Materials, ASTM STP 836: 21-55, 1984.

[32] H. Mao and S. Mahadevan. Fatigue damage modelling of composite materials. Composite Structures, 58(4): 405-410, 2002. 